\title{
Intravenous Oxycodone Versus Other Intravenous Strong Opioids for Acute Postoperative Pain Control: A Systematic Review of Randomized Controlled Trials
}

\author{
Milton Raff (1) - Anissa Belbachir - Salah El-Tallawy - Kok Yuen Ho · \\ Eric Nagtalon · Amar Salti · Jeong-Hwa Seo • Aida Rosita Tantri • \\ Hongwei Wang · Tianlong Wang • Kristal Cielo Buemio • \\ Consuelo Gutierrez • Yacine Hadjiat
}

Received: January 3, 2019 / Published online: April 19, 2019

(C) The Author(s) 2019

\section{ABSTRACT}

Introduction: Optimal pain management is crucial to the postoperative recovery process. We aimed to evaluate the efficacy and safety of intravenous oxycodone with intravenous fentanyl, morphine, sufentanil, pethidine, and hydromorphone for acute postoperative pain.

Methods: A systematic literature search of PubMed, Cochrane Library, and EMBASE databases was performed for randomized controlled trials published from 2008 through 2017

Enhanced Digital Features To view enhanced digital features for this article go to: https://doi.org/10.6084/ m9.figshare.7931558.

Electronic supplementary material The online version of this article (https://doi.org/10.1007/s40122019-0122-4) contains supplementary material, which is available to authorized users.

M. Raff $(\bowtie)$

Pain Clinic, Christiaan Barnard Memorial Hospital, Cape Town, South Africa

e-mail: raffs@iafrica.com

A. Belbachir

Faculté de médecine, Université Paris-Descartes, Pôle d'anesthésie-réanimation, Hôpital Cochin, Paris, France

\section{S. El-Tallawy}

Department of Anesthesia and Pain Management, College of Medicine, King Khalid University

Hospital, King Saud University, Riyadh, Saudi Arabia (inclusive) that evaluated the acute postoperative analgesic efficacy of intravenous oxycodone against fentanyl, morphine, sufentanil, pethidine, and hydromorphone in adult patients (age $\geq 18$ years). Outcomes examined included analgesic consumption, pain intensity levels, side effects, and patient satisfaction.

Results: Eleven studies were included in the review; six compared oxycodone with fentanyl, two compared oxycodone with morphine, and three compared oxycodone with sufentanil. There were no eligible studies comparing oxycodone with pethidine or hydromorphone. Overall, analgesic consumption was lower with oxycodone than with fentanyl or sufentanil. Oxycodone exhibited better analgesic efficacy than fentanyl and sufentanil, and comparable analgesic efficacy to morphine. In terms of safety, there was a tendency towards more side effects with oxycodone than with fentanyl, but

\section{K. Y. Ho}

The Pain Clinic, Mount Alvernia Medical Centre, Singapore, Singapore

\section{E. Nagtalon}

Department of Anesthesia, University of the East Ramon Magsaysay Memorial Medical Center, Quezon City, Philippines

\section{A. Salti}

Anesthesiology Institute, Sheikh Khalifa Medical City, Abu Dhabi, United Arab Emirates 
the incidence of side effects with oxycodone was comparable to morphine and sufentanil. Where patient satisfaction was evaluated, higher satisfaction levels were observed with oxycodone than with sufentanil and comparable satisfaction was noted when comparing oxycodone with fentanyl. Patient satisfaction was not evaluated in the studies comparing oxycodone with morphine.

Conclusions: Our findings suggest that intravenous oxycodone provides better analgesic efficacy than fentanyl and sufentanil, and comparable efficacy to morphine with less adverse events such as sedation. No studies comparing intravenous oxycodone with pethidine or hydromorphone were identified in this review. Better alignment of study methodologies for future research in this area is recommended to provide the best evidence base for a meta-analysis.

Funding: Mundipharma Singapore Holding Pte Ltd, Singapore.

Keywords: Acute postoperative pain; Fentanyl; Hydromorphone; Morphine; Oxycodone; Pethidine; Sufentanil

\section{INTRODUCTION}

The majority of patients who undergo surgical procedures experience acute postoperative pain, with over $80 \%$ reporting moderate-to-severe

\footnotetext{
J.-H. Seo

Department of Anesthesiology and Pain Medicine, Seoul National University Hospital, Seoul National University College of Medicine, Seoul, Korea

A. R. Tantri

Department of Anesthesiology and Intensive Care, Universitas Indonesia, Dr. Ciptomangunkusumo

National General Hospital, Jakarta, Indonesia

H. Wang

Department of Anesthesiology, Tongde Hospital of Zhejiang Province, Hangzhou, Zhejiang, China

T. Wang

Department of Anesthesiology, Xuanwu Hospital of

Capital Medical University, Beijing, China

K. C. Buemio - C. Gutierrez · Y. Hadjiat

Mundipharma Singapore Holding Pte. Ltd.,

Singapore, Singapore
}

pain [1]. Acute postoperative pain is multimechanistic and may consist of both nociceptive and neuropathic pain [2]. Inadequate postoperative pain control may impede recovery and delay rehabilitation, leading to poor outcomes [3]. Effective pain management is thus central to the postoperative recovery process and can help improve patient comfort, enhance tissue healing, and promote early discharge $[4,5]$.

Analgesia administered by the intravenous route is typically used in the early postoperative period when administration by the oral route is less feasible [6]. In the case of moderately severe-to-severe acute postoperative pain, clinical practice guidelines recommend the use of strong opioids such as oxycodone, morphine, fentanyl, or hydromorphone as part of the multimodal analgesic approach [7-12]. The strong opioids, sufentanil and pethidine, are less widely recommended-sufentanil due to its short duration of action and pethidine due to safety concerns. The unfavorable risk-benefit profile of pethidine has led to a gradual decline of its use for peri-operative analgesia in developed countries [13, 14]. Many government, professional, and accreditation agencies view the use of pethidine as an indicator of poor quality of care [14]; however, pethidine is still extensively used in regions composed largely of low- and middle-income countries (such as Africa, Eastern Mediterranean, and South-East Asia) [13].

Pharmacological properties vary amongst strong opioids (Table 1). Choosing between these opioids is challenging when used for postoperative analgesia as there is little evidence to support the use of one opioid analgesic over another. Intravenous morphine is traditionally the opioid of choice, but oxycodone is being increasingly utilized [15-17]. Unlike most strong opioids that act primarily through the $\mu$ opioid receptor to induce analgesia [18, 19], oxycodone has additional agonistic effects on the $\kappa-$ and $\delta$-opioid receptors [20-22]; its additional action on the $\kappa$-receptor has been suggested to be of particular significance for antinociception in the visceral pain system [23-26]. Some studies also suggest that oxycodone has an enhanced analgesic effect on neuropathic 
Table 1 Pharmacological properties of oxycodone, morphine, fentanyl, sufentanil, pethidine, and hydromorphone

\begin{tabular}{|c|c|c|c|c|c|c|}
\hline & $\begin{array}{l}\text { Oxycodone } \\
{[21,22,53-58]}\end{array}$ & $\begin{array}{l}\text { Morphine } \\
\text { [59-61] }\end{array}$ & $\begin{array}{l}\text { Fentanyl } \\
{[59,61-63]}\end{array}$ & $\begin{array}{l}\text { Sufentanil } \\
{[64-67]}\end{array}$ & $\begin{array}{l}\text { Pethidine } \\
{[61,68-70]}\end{array}$ & $\begin{array}{l}\text { Hydromorphone } \\
{[71,72]}\end{array}$ \\
\hline \multicolumn{7}{|l|}{ Absorption } \\
\hline$T_{\max }$ & $6-25 \mathrm{~min}$ & $19 \mathrm{~min}$ & $4 \mathrm{~min}$ & $6 \mathrm{~min}$ & $1.2 \mathrm{~min}$ & $20 \mathrm{~min}$ \\
\hline \multicolumn{7}{|l|}{ Distribution } \\
\hline $\begin{array}{l}\text { Plasma } \\
\text { protein } \\
\text { binding }\end{array}$ & $45 \%$ & $35-36 \%$ & $84 \%$ & $\sim 90 \%$ & $\sim 58 \%$ & $8-19 \%$ \\
\hline$V_{\mathrm{D}}$ & $2-31 / \mathrm{kg}$ & $1-4.7 \mathrm{l} / \mathrm{kg}$ & $4 \mathrm{l} / \mathrm{kg}$ & $1.7-5.2 \mathrm{l} / \mathrm{kg}$ & $3-51 / \mathrm{kg}$ & 302.91 \\
\hline \multicolumn{7}{|l|}{ Metabolism } \\
\hline $\begin{array}{l}\text { Major } \\
\text { metabolites }\end{array}$ & $\begin{array}{l}\text { Noroxycodone, } \\
\text { oxymorphone }\end{array}$ & $\begin{array}{l}\text { Morphine-3- } \\
\text { glucuronide }\end{array}$ & Norfentanyl & Norfentanyl & Norpethidine & $\begin{array}{l}\text { Hydromorphone- } \\
\text { 3-glucuronide }\end{array}$ \\
\hline \multicolumn{7}{|l|}{ Excretion } \\
\hline $\mathrm{Cl}$ & $1.10 \mathrm{l} / \mathrm{min}$ & $0.9-1.2 \mathrm{l} / \mathrm{kg} / \mathrm{h}$ & $\begin{array}{c}0.8-1.0 \mathrm{ml} / \\
\mathrm{min} / \mathrm{kg}\end{array}$ & $57.6 \mathrm{l} / \mathrm{h}$ & $20.5 \mathrm{l} / \mathrm{h}$ & $1.96 \mathrm{l} / \mathrm{min}$ \\
\hline$T_{1 / 2}$ & $2-3.5 \mathrm{~h}$ & $1.5-4.5 \mathrm{~h}$ & $3.7 \mathrm{~h}$ & $2.7 \mathrm{~h}$ & $2-5 \mathrm{~h}$ & $2.3 \mathrm{~h}$ \\
\hline \multicolumn{7}{|c|}{ Opioid receptor action } \\
\hline$\mu$ & +++ & +++ & +++ & +++ & +++ & +++ \\
\hline$\kappa$ & ++ & + & + & + & + & Nil \\
\hline$\delta$ & ++ & + & Nil & + & + & + \\
\hline
\end{tabular}

$\mathrm{Cl}$, clearance; $T_{\max }$, time to maximum plasma concentration; $T_{1 / 2}$, half-life; $V_{\mathrm{D}}$, volume of distribution; $\mu$, mu-opioid receptor; $\kappa$, kappa-opioid receptor; $\delta$, delta-opioid receptor

pain $[27,28]$. Furthermore, oxycodone has been reported to be faster-acting than morphine [29], and to provide longer-lasting analgesic effect when compared with fentanyl $[30,31]$ and morphine [32].

Given the increasing clinical use of oxycodone for the management of acute postoperative pain, further understanding is needed regarding the efficacy and safety of oxycodone versus other strong opioids. This systematic review aims to summarize and synthesize the findings of recent head-to-head randomized controlled trials (RCTs) comparing the efficacy and safety of oxycodone with other strong opioids (in particular, morphine, fentanyl, sufentanil, hydromorphone, and pethidine) in the management of acute postoperative pain.

\section{METHODS}

\section{Literature Search Strategy}

A search of PubMed, Cochrane Library, and EMBASE databases was conducted for studies published from 2008 through 2017 that evaluated the acute postoperative analgesic efficacy of the parenteral oxycodone compared with morphine, fentanyl, sufentanil, pethidine, or hydromorphone. The search terminology included a variety of terms and medical subject 
headings for post-operative, analgesia, injection, oxycodone, morphine, fentanyl, sufentanil, pethidine, hydromorphone, and RCTs. Search strategies were developed specifically for each database. The full list of database-specific search queries is presented in Supplementary Table 1. The bibliographies of included articles were also screened for potentially relevant publications.

\section{Selection of Studies}

All articles identified in the search were screened by title and abstract for relevance. Following the initial screening, the full-text articles of potentially relevant publications were evaluated for inclusion in the review. Articles were included if they fulfilled all of the inclusion criteria and contained none of the exclusion criteria. Inclusion criteria were as follows: RCTs; adult patients ( $\geq 18$ years of age) with postoperative pain; administration of analgesics after operation; treatment with intravenous oxycodone and either intravenous morphine, fentanyl, sufentanil, pethidine, or hydromorphone; and published between 2008 and 2017 (inclusive). Exclusion criteria were as follows: non-human studies; treatment with modified release formulations (e.g., controlled-release morphine, transdermal fentanyl); interventions used to treat pre-existing pain other than the acute postoperative pain; interventions used as pre-emptive analgesia or rescue therapy; nonEnglish articles; and pediatric patients.

\section{Assessment of Study Quality}

The quality of included studies was assessed using the Jadad scale, which assesses each study according to three main categories: randomization ( 2 points), blinding ( 2 points), and attrition (1 point). Each included study was scored from 0 (lowest quality) to 5 (highest quality), depending on method of randomization, blinding, and description for attrition. Studies which scored four or more points were considered to be of high-quality. This article is based on previously conducted studies and does not contain any studies with human participants or animals performed by any of the authors.

\section{RESULTS}

\section{Study Inclusion}

Figure 1 shows the flow of the screening and evaluation process. The systematic literature search identified 450 publications. Ten studies met the eligibility criteria. One additional study recently published was included based on experts' recommendation after the search was conducted. No additional studies were identified from the bibliographic search of relevant articles.

Of the 11 included studies, six compared oxycodone with fentanyl, two compared oxycodone with morphine, and three compared oxycodone with sufentanil. No studies comparing oxycodone with pethidine or hydromorphone were identified from the literature search.

\section{Study Characteristics and Findings}

Characteristics of all the included studies such as reference (year), country, type of surgery, study duration, route of administration, treatment groups, dose conversion ratio, and reported outcomes are presented in Table 2 . Specific study characteristics are detailed in the following sections accordingly. Key findings of the included studies are summarized in Table 3.

\section{Oxycodone vs. Fentanyl}

Six studies involving a total of 466 patients from the Republic of Korea, China, and Denmark, compared oxycodone with fentanyl for acute postoperative pain (Table 2). Surgical procedures included laparoscopic hysterectomy [33-35], laparoscopic myomectomy [35], laparoscopic cholecystectomy [30, 31], and gastrointestinal laparotomy [36]. The follow-up duration in all studies was $48 \mathrm{~h}$ after surgery, except for the study by Koch et al. [30], which monitored patients until discharge from the post-anesthesia care unit. Opioids were administered via intravenous patient-controlled analgesia (IV-PCA) [31, 33-36], and IV bolus [30]. The dose conversion ratios used for oxycodone 


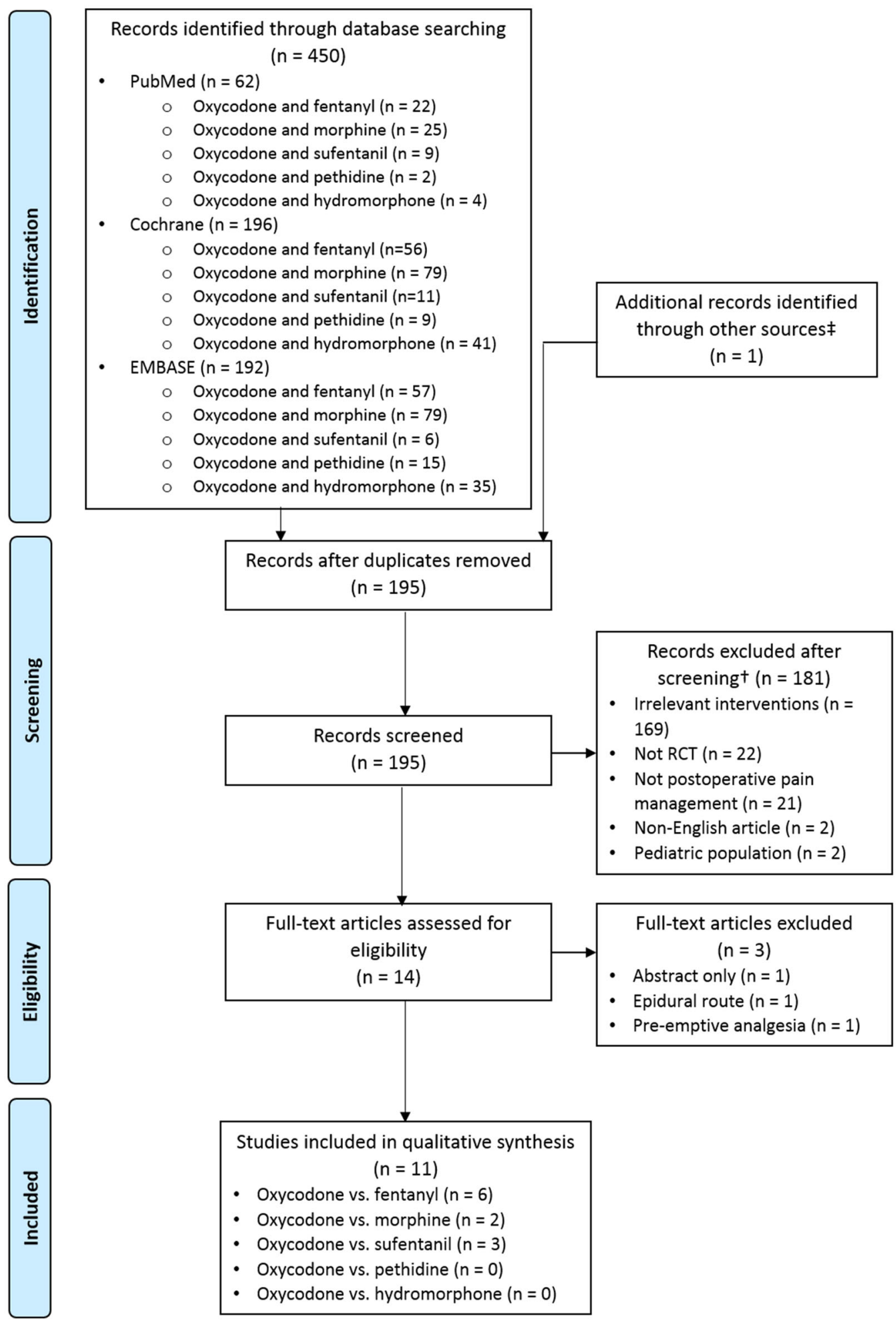

† Numbers may not add up to 181 as articles may have been excluded based on one or more screening criteria

‡ One study was included based on experts' recommendation after the systematic literature search was conducted

Fig. 1 Flow diagram of the literature screening and evaluation process 


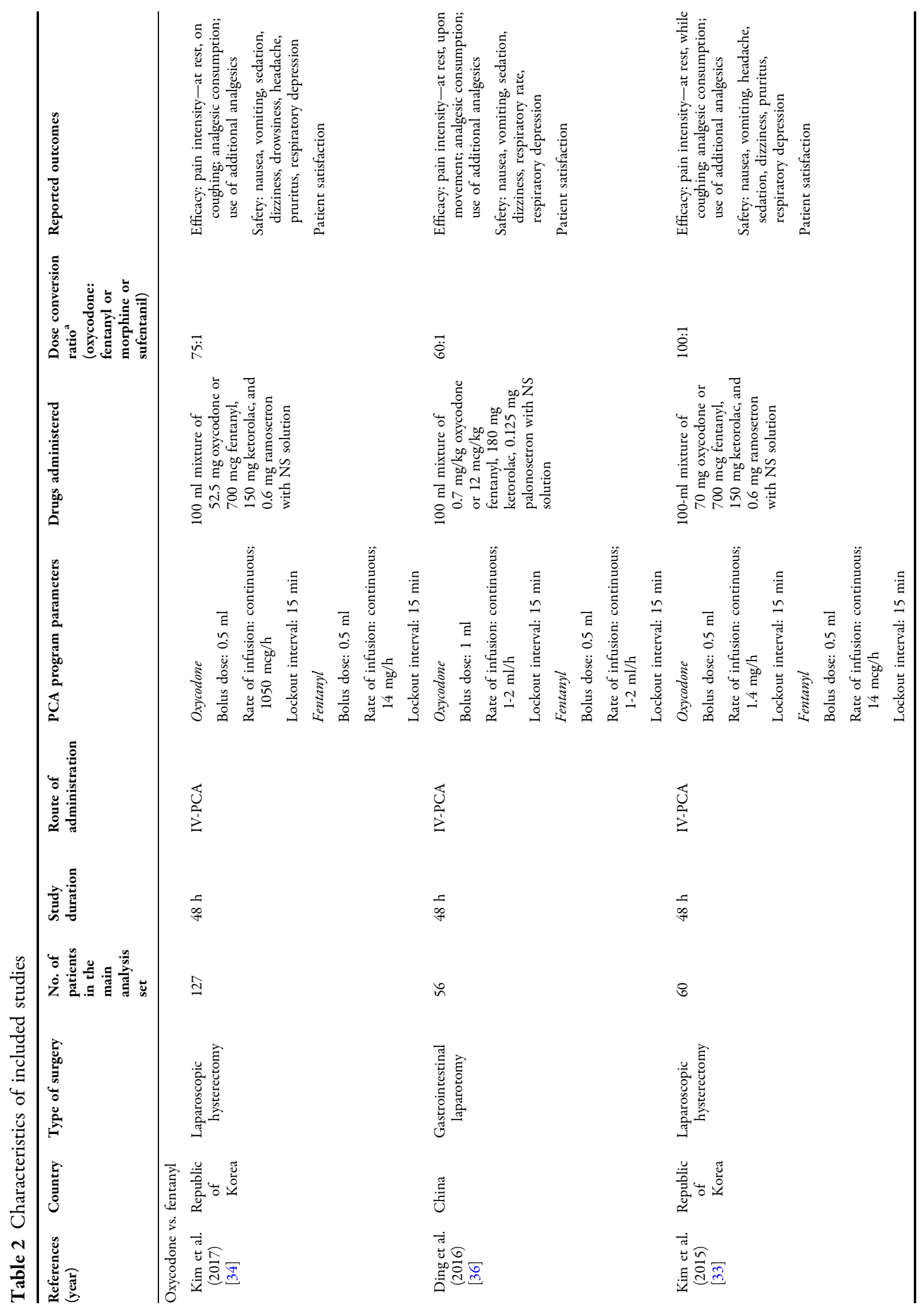




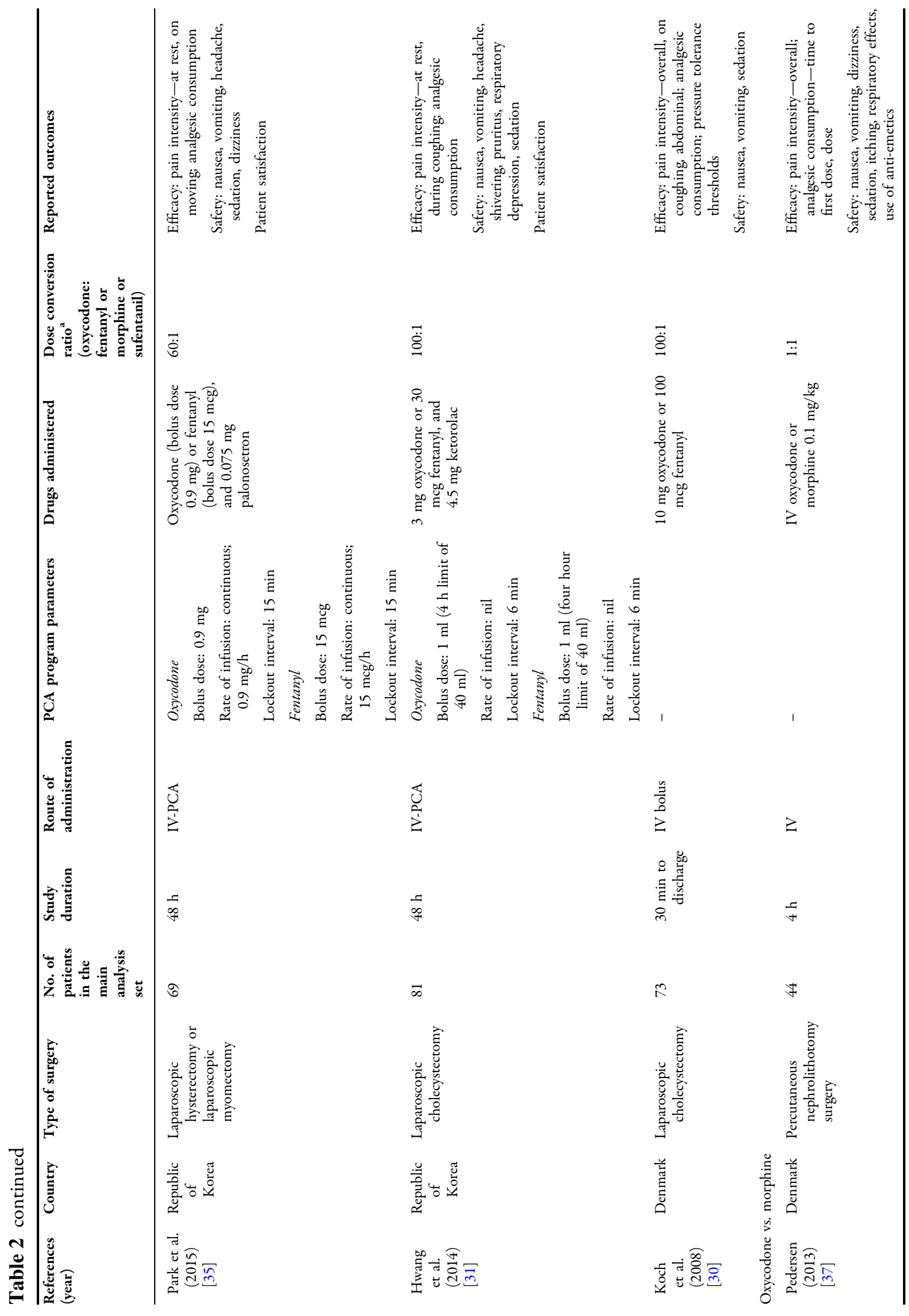




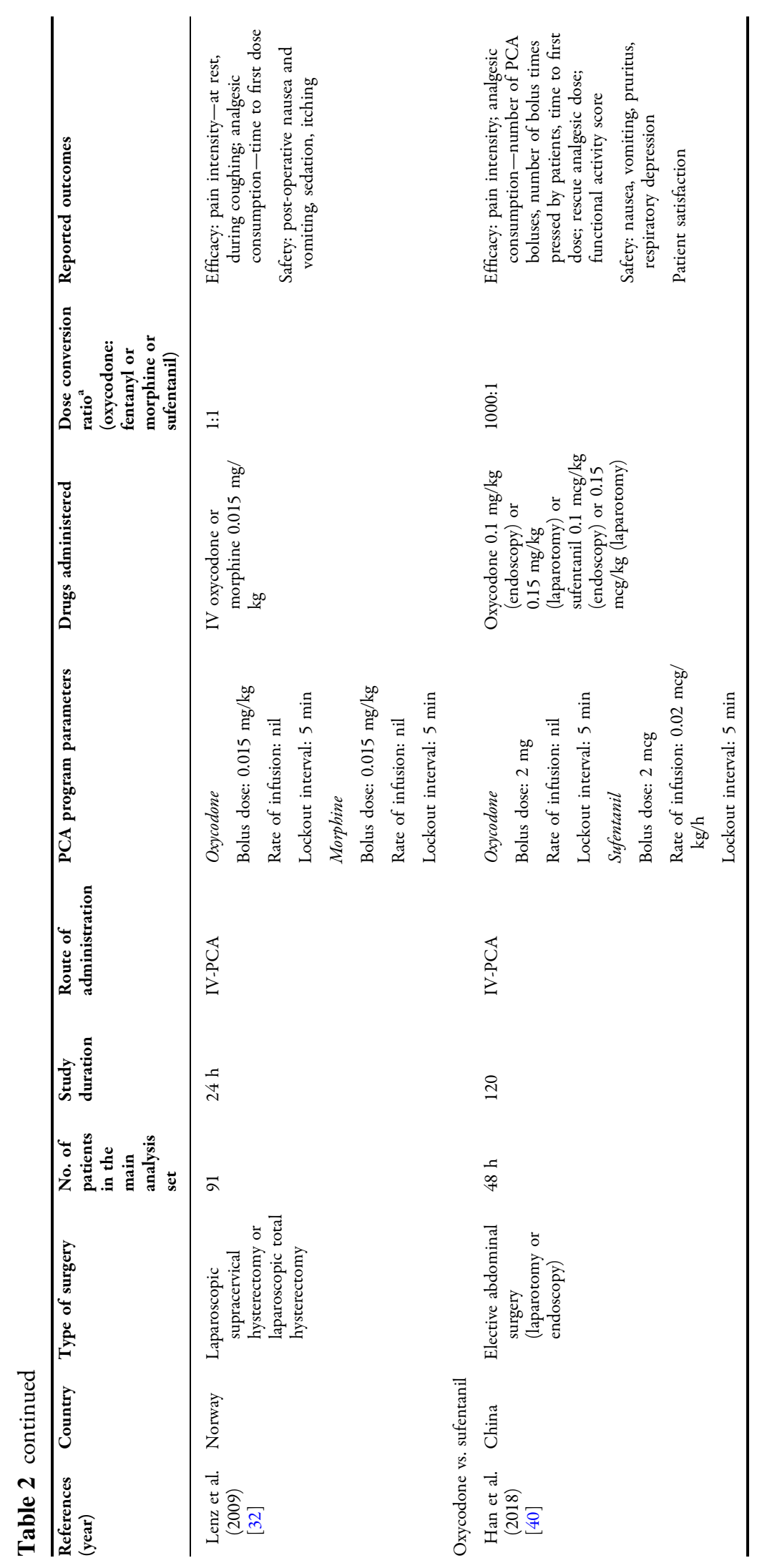




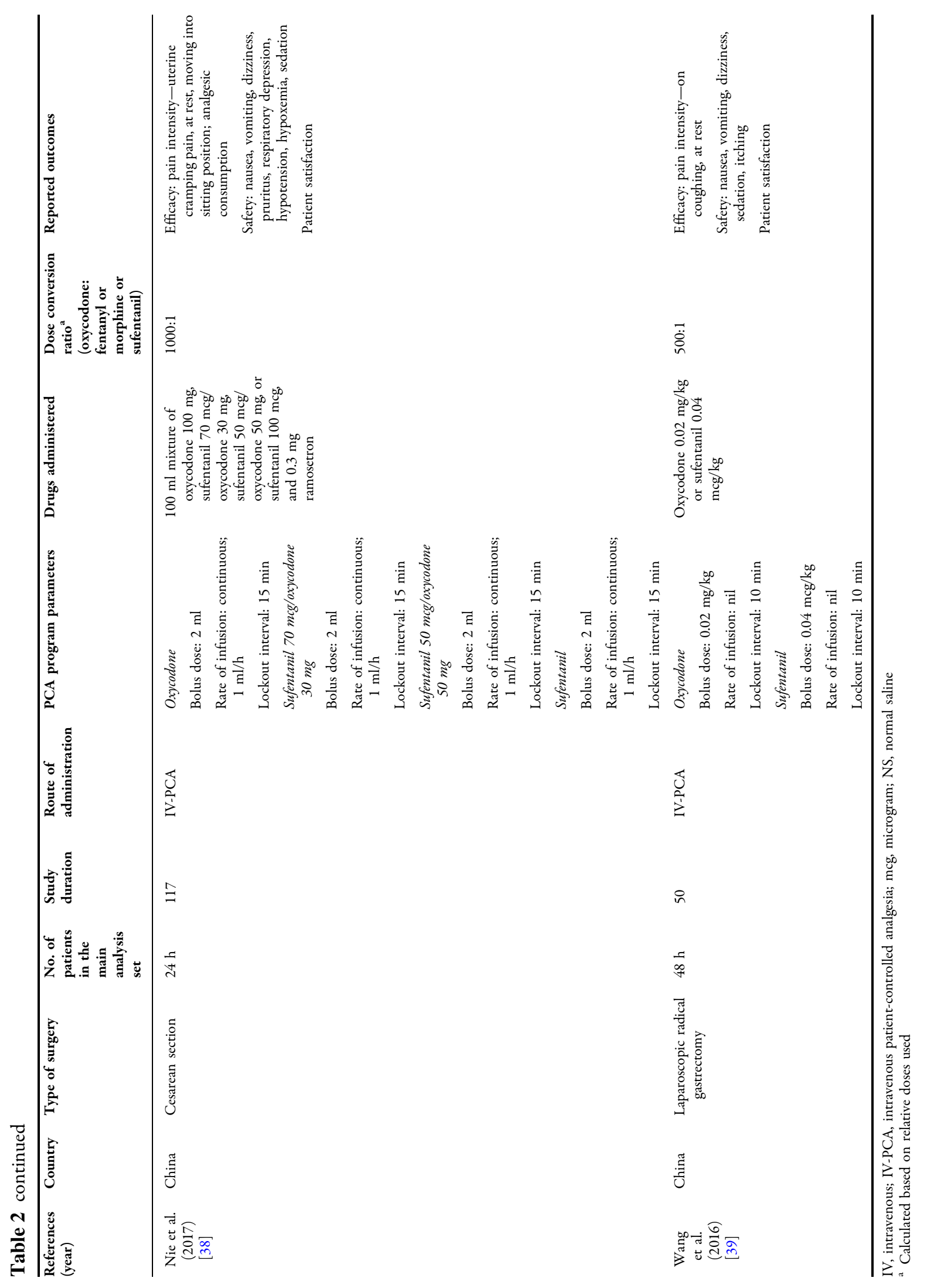


Table 3 Comparison of key findings of oxycodone with fentanyl, morphine, and sufentanil in included studies

\begin{tabular}{|c|c|c|c|c|c|}
\hline \multirow[t]{2}{*}{ Studies } & \multirow{2}{*}{$\begin{array}{l}\text { First author } \\
\text { (year) }\end{array}$} & \multicolumn{2}{|l|}{ Efficacy } & \multirow{2}{*}{$\begin{array}{l}\text { Safety } \\
\text { Side effects }\end{array}$} & \multirow{2}{*}{$\begin{array}{l}\text { Patient } \\
\text { preference } \\
\text { Satisfaction }\end{array}$} \\
\hline & & $\begin{array}{l}\text { Pain } \\
\text { intensity }\end{array}$ & $\begin{array}{l}\text { Analgesic } \\
\text { consumption }\end{array}$ & & \\
\hline \multirow[t]{6}{*}{$\begin{array}{l}\text { Oxycodone vs. } \\
\text { fentanyl }\end{array}$} & $\begin{array}{l}\text { Kim et al. (2017) } \\
{[34]}\end{array}$ & $\mathrm{O}$ & $\mathrm{O}$ & F (nausea, dizziness) & $\begin{array}{l}\text { Comparable/ } \\
\text { F }\end{array}$ \\
\hline & $\begin{array}{l}\text { Ding et al. (2016) } \\
\text { [36] }\end{array}$ & $\mathrm{O}$ & $\mathrm{F}$ & Comparable/O (sedation) & Comparable \\
\hline & $\begin{array}{l}\text { Kim et al. (2015) } \\
\text { [33] }\end{array}$ & $\begin{array}{l}\text { Comparable/ } \\
\text { O }\end{array}$ & Comparable/O & Comparable/F (nausea) & Comparable \\
\hline & $\begin{array}{l}\text { Park et al. (2015) } \\
\text { [35] }\end{array}$ & $\mathrm{O}$ & $\mathrm{O}$ & Comparable/F (dizziness) & $\mathrm{O}$ \\
\hline & $\begin{array}{l}\text { Hwang et al. } \\
(2014)[31]\end{array}$ & Comparable & $\mathrm{O}$ & Comparable/F (nausea) & Comparable \\
\hline & $\begin{array}{l}\text { Koch et al. (2008) } \\
\text { [30] }\end{array}$ & $\mathrm{O}$ & $\mathrm{O}$ & Comparable & - \\
\hline \multirow[t]{2}{*}{$\begin{array}{l}\text { Oxycodone vs. } \\
\text { morphine }\end{array}$} & $\begin{array}{l}\text { Pedersen et al. } \\
(2013)[37]\end{array}$ & Comparable & Comparable & Comparable & - \\
\hline & $\begin{array}{l}\text { Lenz et al. (2009) } \\
\text { [32] }\end{array}$ & $\begin{array}{l}\text { Comparable/ } \\
\text { O }\end{array}$ & $\mathrm{O}$ & Comparable/O (sedation) & - \\
\hline \multirow[t]{3}{*}{$\begin{array}{l}\text { Oxycodone vs. } \\
\text { sufentanil }\end{array}$} & $\begin{array}{l}\text { Han et al. (2018) } \\
\quad[40]\end{array}$ & Comparable & $\mathrm{O}$ & O (nausea, vomiting) & $\mathrm{O}$ \\
\hline & $\begin{array}{l}\text { Nie et al. (2017) } \\
\text { [38] }\end{array}$ & $\mathrm{O}$ & $\mathrm{O}$ & $\begin{array}{l}\text { Comparable/O (nausea, } \\
\text { vomiting, pruritus) }\end{array}$ & $\mathrm{O}$ \\
\hline & $\begin{array}{l}\text { Wang et al. (2016) } \\
\text { [39] }\end{array}$ & Comparable & $\mathrm{O}$ & Comparable & $\mathrm{O}$ \\
\hline
\end{tabular}

Table illustrates opioid that fared better in terms of the outcomes listed; specific side effects are listed in parentheses "Comparable" was listed if a set of comparator drugs in a particular study fared similarly for an outcome

"-" Was listed if the outcome was not evaluated

F, fentanyl; M, morphine; O, oxycodone

to fentanyl were 100:1 [30, 31, 33], 60:1 [35, 36], and 75:1 [34]. Outcomes collected for efficacy included pain intensity at rest and during movement or coughing; while those for safety included side effects such as nausea, vomiting, sedation, and dizziness; and patient satisfaction.

\section{Efficacy: Pain Intensity}

Oxycodone exhibited greater analgesic efficacy than fentanyl, especially at earlier time points. In three studies, pain relief was significantly better with oxycodone than with fentanyl from as early as 30 min after surgery [30, 33, 36]. Pain relief remained significantly better with oxycodone for $24 \mathrm{~h} \mathrm{[33]} \mathrm{to} 48 \mathrm{~h}$ after surgery [36], or until discharge from the post-anesthesia care 
unit [30]. Two studies reported significantly better postoperative pain relief with oxycodone compared with fentanyl between 4 and $8 \mathrm{~h}$ after surgery [34, 35], however, no significant analgesic difference between groups was observed thereafter. The remaining study by Hwang et al. found comparable pain scores between oxycodone and fentanyl at rest and during coughing from $4 \mathrm{~h}$ to $48 \mathrm{~h}$ during the postoperative period [31].

\section{Efficacy: Analgesic Consumption}

Amongst the five studies that used IV-PCA, four reported on the quantity of opioid consumed [31, 33-35]. All four studies that used dose conversion ratios (oxycodone:fentanyl) between 60:1 and 100:1 observed significantly less analgesic consumption with oxycodone than with fentanyl during the first $48 \mathrm{~h}$ after surgery [31, 33-35]. Of three studies which evaluated analgesic consumption at various time points during the 48 -h postoperative period [31, 33, 34], two reported significantly lower cumulative IV-PCA volumes with oxycodone than with fentanyl from 8 to $48 \mathrm{~h}[31,33]$, however, no significant difference was reported between groups during the first $4 \mathrm{~h}$ after surgery $[31,33,34]$.

Three studies reported data on the use of additional/rescue analgesics during the postoperative period. Of these, two found that the use of rescue analgesics was significantly more frequent with fentanyl than with oxycodone $[33,34]$, whereas one found no significant difference between these agents [36].

\section{Safety: Side Effects}

Six studies compared the common opioid-related side effects of oxycodone with those of fentanyl in acute postoperative pain management. Overall, there was a tendency towards a lower occurrence of some side effects with fentanyl than with oxycodone (Table 3 ). It should be noted, however, that none of the studies were specifically designed to assess differences in side effects between opioid groups and are thus likely underpowered (i.e., inadequate sample size) to do so.

\section{Nausea}

All except one study [21] administered antiemetics before the end of surgery as prophylaxis against postoperative nausea and vomiting. Antiemetics were also provided in the postoperative care unit in all but one study [23]. Although most of the patients in these studies would have received antiemetic treatment at the end of surgery, at least $10 \%$ of patients in both treatment groups still experienced postoperative nausea and vomiting.

The overall incidence of postoperative nausea with oxycodone ranged from 14.8 to $53.7 \%$, while that with fentanyl ranged from 10.3 to $35 \%$ across four studies [30, 31, 35, 36]. Three of these studies reported higher incidences of nausea with oxycodone than with fentanyl, but these differences were not statistically significant $[30,35,36]$. Three other studies that evaluated the incidence of nausea at various time points showed a significantly higher incidence of nausea with oxycodone than with fentanyl starting from as early as $2 \mathrm{~h}$ [33] and $4 \mathrm{~h}$ [34] after surgery, and between 6 and $24 \mathrm{~h}$ after surgery [23].

\section{Vomiting}

The incidence of postoperative vomiting with oxycodone ranged from 3.7 to $14 \%$, while that with fentanyl ranged from 3 to $5 \%$ across three studies [30, 35, 36]. Vomiting associated with oxycodone occurred significantly more frequently than with fentanyl at $8 \mathrm{~h}$ postoperatively [34]. The incidence of vomiting with oxycodone and fentanyl was found to be comparable by Ding et al. (3.7 vs. 3.4\%) [36], and by Kim et al. at all-time points [33]. Hwang et al. noted no reports of vomiting with either treatment [31].

\section{Pruritus}

The incidence of pruritus with oxycodone ranged from 2.4 to $14.0 \%$, while that with fentanyl 
ranged from 4.8 to $10.0 \%$ across three studies [31, 33, 34]. Hwang et al. reported a lower incidence of pruritus with oxycodone than with fentanyl (2.4 vs. $7.5 \%)$, but this result was not statistically significant [31]. A higher incidence of pruritus was observed with oxycodone than with fentanyl by Kim et al. (14.0 vs. $4.8 \%$ [34]) and Kim et al. (13.3 vs. 10.0\% [33]), but these differences were not statistically significant.

\section{Sedation}

Sedation was assessed in all studies, but Hwang et al. did not report incidence rates of sedation in their study [31]. The incidence of sedation with oxycodone ranged from 11 to $38 \%$, while that with fentanyl ranged from 3.2 to $69.0 \%$ across five studies [30, 33-36]. Only Ding et al. found the incidence of sedation with fentanyl to be significantly higher than that with oxycodone (69 vs. 11\%) [36]. The other five studies found sedation levels to be comparable between oxycodone and fentanyl [30, 31, 33-35].

\section{Dizziness}

Four studies assessed the incidence of dizziness [33-36]. The incidence of dizziness with oxycodone ranged from 22.2 to $67.1 \%$, while that with fentanyl ranged from 10 to $25.3 \%$ across four studies [33-36]. Two studies found dizziness with oxycodone to be significantly higher than with fentanyl $[34,35]$, while two other studies found comparable incidences of dizziness between groups [33, 36].

\section{Respiratory Effects}

There were no reports of respiratory depression with either treatment in all four studies that evaluated respiratory effects $[31,33,34,36]$. Additionally, respiration rate over $48 \mathrm{~h}$ was found to be comparable between treatment groups [36].

\section{Other Side Effects}

Three studies assessed the incidence of headache. The incidence of headache with oxycodone ranged from 13.3 to $19.0 \%$, while that with fentanyl ranged from 3.0 to $14.3 \%$ across three studies. Park et al. reported a higher incidence of headaches with oxycodone than with fentanyl (19 vs. $3 \%)$, but this difference was not statistically significant [35]. The other two studies reported comparable incidences of headache with oxycodone and fentanyl $[33,34]$.

Hwang et al. [31] also assessed the incidence of shivering. In the oxycodone group, only one patient (2.4\%) experienced shivering while none in the fentanyl group experienced shivering [31]. This difference between treatment groups was not statistically significant.

\section{Patient Satisfaction}

Five of six studies that compared oxycodone with fentanyl evaluated patient satisfaction. The proportion of patients who were satisfied with oxycodone ranged from 53.0 to $82.9 \%$, while that for patients who were satisfied with fentanyl ranged from 55.2 to $85.7 \%$ across four studies [31, 33, 34, 36]. Park et al. found that satisfaction with pain control at $6 \mathrm{~h}$ after the surgery was significantly higher with oxycodone than with fentanyl [mean (SD) 3.9 (1.0) vs. 3.2 (1.1); $P<0.05]$, although satisfaction at other time points was comparable [35]. On the other hand, Kim et al. reported higher patient satisfaction with fentanyl than with oxycodone at $48 \mathrm{~h}$ (85.7 vs. 53.0\%) [34]. The remaining three studies did not find any significant differences in patient satisfaction between treatment groups [31, 33, 36].

\section{Oxycodone vs. Morphine}

Two studies involving a total of 135 patients from Denmark and Norway compared oxycodone with morphine for acute postoperative pain (Table 2). Surgical procedures included percutaneous nephrolithotomy [37] and laparoscopic supracervical hysterectomy or 
laparoscopic total hysterectomy [32]. Study durations were $4 \mathrm{~h}$ [37] and $24 \mathrm{~h}$ [32]. Opioids were administered via IV [37] and IV-PCA [32] routes. The dose conversion ratio used for oxycodone to morphine was 1:1 in both studies $[32,37]$. Outcomes collected for efficacy included pain intensity at rest and during movement or coughing; those for safety included side effects such as nausea, vomiting, sedation, and dizziness; and patient satisfaction.

\section{Efficacy: Pain Intensity}

Both studies compared the analgesic effect of oxycodone with morphine for the management of acute postoperative pain. One of these studies found comparable analgesic effect between treatment groups [37]. Another study reported less pain on coughing with oxycodone than with morphine during the first postoperative hour [32].

\section{Efficacy: Analgesic Consumption}

Both studies compared the analgesic consumption of oxycodone with morphine for managing postoperative pain. One of these studies found comparable opioid consumption between treatment groups [37]; although the mean time to first opioid dosing with oxycodone tended to be shorter than with morphine, the difference was not statistically significant [37]. The remaining study found significantly less cumulative oxycodone consumption compared with morphine consumption [mean (SD) $13.3 \pm 10.4 \mathrm{mg}$ vs. $22.0 \pm 13.1 \mathrm{mg} ; P=0.001)$ and significantly longer mean time from emergence to first use of PCA with oxycodone than with morphine (20 min vs. $16 \mathrm{~min} ; P=0.038$ ) [32].

\section{Safety: Side Effects}

Both studies compared the incidence of common opioid-related side effects of oxycodone with morphine for the management of acute postoperative pain. Overall, the tolerability profile was comparable (Table 3 ). It should be noted, however, that none of the studies were specifically designed to assess differences in side effects between opioid groups and are thus likely underpowered (i.e., inadequate sample size) to do so.

\section{Nausea}

Antiemetics were administered as prophylaxis for postoperative nausea and vomiting in the two studies [32, 37]. Despite antiemetic prophylaxis, at least $15 \%$ of patients in both treatment groups still experienced postoperative nausea and vomiting. Pedersen et al. reported a significantly higher incidence of nausea with oxycodone than with morphine (55 vs. 23\%) [37], whereas Lenz et al. reported no significant differences between treatment groups [32].

\section{Vomiting}

In the study by Pedersen et al., the incidence of vomiting between treatment groups was comparable at $9 \%$ [37]. The study by Lenz et al. also reported no significant differences between treatment groups [32].

\section{Pruritus}

Pedersen et al. reported no incidence of pruritus in either treatment group [37]. Although no data for the incidence of postoperative pruritus was provided, Lenz et al. noted comparable incidences of pruritus between both treatment groups [32].

\section{Sedation}

Lenz et al. reported that the overall incidence of postoperative sedation was significantly lower with oxycodone than with morphine $(P<0.05)$ [32]. Pedersen et al. noted comparable incidence of sedation between treatment groups (oxycodone: $86 \%$ vs. morphine: 73\% [37]).

\section{Dizziness}

Dizziness was only assessed in the study by Pedersen et al. and the incidence was found to 
be comparable between treatment groups (oxycodone: 59\%; morphine: 50\%) [37].

\section{Respiratory Effects}

Respiratory effects were only assessed in the study by Pedersen et al. and the incidence was found to be comparable between treatment groups (oxycodone: 41.0\%; morphine: $23.0 \%$ ) [37].

\section{Patient Satisfaction}

None of the included studies evaluated patient satisfaction.

\section{Oxycodone vs. Sufentanil}

Three studies involving a total of 287 patients from China compared oxycodone with sufentanil for acute postoperative pain (Table 2). Surgical procedures included Cesarean section [38], laparoscopic radical gastrectomy [39], and laparotomic or endoscopic elective abdominal surgery [40]. Study durations were $24 \mathrm{~h}$ [30] and $48 \mathrm{~h}[38,40]$. Opioids were administered via IVPCA in all three studies. The dose conversion ratios used for oxycodone to sufentanil were 1000:1 [38, 40] and 500:1 [39]. Outcomes collected for efficacy included pain intensity (at rest and during movement or coughing) and analgesic consumption [38, 40]; those for safety included side effects such as nausea, vomiting, sedation, dizziness, and patient satisfaction.

\section{Efficacy: Pain Intensity}

All three studies compared the analgesic effect of oxycodone with sufentanil for managing acute postoperative pain (Table 3 ). Wang et al. [39] and Han et al. [40] found that oxycodone and sufentanil provided comparable postoperative analgesia. However, in Nie et al., uterine cramping pain scores and pain during movement were significantly lower with oxycodone than with sufentanil at all time points after Cesarean delivery [38].

\section{Efficacy: Analgesic Consumption}

All three studies compared the analgesic consumption of oxycodone with sufentanil for managing acute postoperative pain. All studies demonstrated significantly higher consumption of sufentanil PCA doses than of oxycodone PCA doses [38-40].

\section{Safety: Side Effects}

All three studies compared the common opioidrelated side effects of oxycodone with those of sufentanil for managing acute postoperative pain. In two studies, safety outcomes were comparable between oxycodone and sufentanil $[38,39]$, whereas in the study by Han et al., there was a tendency towards a lower occurrence of side effects with oxycodone than with sufentanil [40] (Table 3). It should be noted, however, that none of the studies were specifically designed to assess differences in side effects between opioid groups and are thus likely underpowered (i.e., inadequate sample size) to do so.

\section{Nausea}

Antiemetics were administered as prophylaxis against postoperative nausea and vomiting in the studies by Nie et al. [38] and Wang et al. [39], but not in the study by Han et al. [40]. Despite antiemetic prophylaxis, some patients still experienced postoperative nausea and vomiting.

All three studies assessed the incidence of nausea for oxycodone and sufentanil. In the study by Han et al., the incidence of nausea was assessed at three time points: 3,24 , and $48 \mathrm{~h}$ [40]. At all time points, the incidence of nausea was significantly lower with oxycodone than with sufentanil [40]. By contrast, Nie et al. and Wang et al. showed that there was no statistically significant difference in the incidence of nausea between oxycodone and sufentanil (0.0 vs. $16.7 \%$ [38]; and 12 vs. $16 \%$ [39], respectively). 


\section{Vomiting}

In the studies by Nie et al. [38] and Wang et al. [39], no patients on oxycodone reported vomiting. There were no reports of vomiting with sufentanil by Nie et al. [38]; however, $4 \%$ of patients who received sufentanil in the study by Wang et al. experienced vomiting [39]. In the study by Han et al., the incidence of vomiting was assessed at three time points: 3, 24, and $48 \mathrm{~h} \mathrm{[40].} \mathrm{At} 3$ and $24 \mathrm{~h}$, the incidence of vomiting was significantly lower with oxycodone than with sufentanil.

\section{Pruritus}

There were no reports of pruritus with either oxycodone or sufentanil in the study by Nie et al. [38]. Wang et al. noted no reports of pruritus with oxycodone; however, one of 25 patients (4\%) who received sufentanil experienced pruritus [39]. In the study by Han et al., the incidence of pruritus was assessed at three time points: 3, 24, and $48 \mathrm{~h}$ [40]. At all time points, fewer patients on oxycodone experienced pruritus than those on sufentanil; however, this difference was not significant.

\section{Sedation}

Wang et al. noted no reports of sedation with oxycodone; however, one of 25 patients (4\%) who received sufentanil experienced sedation [39]. All patients in the Nie et al. study experienced light sedation (Ramsay sedation score of $2)$, regardless of treatment with oxycodone or sufentanil [38]. None of these results were statistically significant. The incidence of sedation was not assessed by Han et al. [40].

\section{Dizziness}

Reports on the incidence of dizziness in two studies were conflicting. Nie et al. noted that three patients (10.3\%) experienced dizziness with oxycodone, whereas no patients on sufentanil experienced this side effect [38]. In contrast, the other study reported $12 \%$ of patients on sufentanil experienced dizziness compared with $8 \%$ of those on oxycodone [39]. None of these results were statistically significant.

\section{Respiratory Effects}

Respiratory depression was assessed in two studies. Nie et al. reported that no patients in either treatment group experienced respiratory depression [38]. Han et al. reported that throughout the study, only one patient treated with sufentanil experienced respiratory depression at $3 \mathrm{~h}$, whereas no patients treated with oxycodone experienced respiratory depression at any time points $(3,24$, and $48 \mathrm{~h})$ [40].

\section{Other Side Effects}

Hypotension and hypoxemia were assessed by Nie et al.; no patients in either treatment group experienced hypotension or hypoxemia [38].

\section{Patient Satisfaction}

All three studies compared patient satisfaction between oxycodone and sufentanil for managing acute postoperative pain. All studies demonstrated greater patient satisfaction with oxycodone than with sufentanil [38-40] (Table 3).

\section{Quality of Included Studies}

The quality of included studies is summarized in Supplementary Table 2. Overall, ten of the 11 included studies were considered to be of high quality.

Of the six studies comparing oxycodone with fentanyl, five scored at least four points. All six studies mentioned randomization [30, 31, 33-36], and five mentioned blinding [30, 31, 34-36], although two studies and one study had not described the methods used for randomization [31, 33] and blinding [33], respectively. Attrition was described in five of six studies [30, 31, 34-36]. 
All studies comparing oxycodone with morphine and sufentanil scored at least four points, which was considered to be of high quality. Attrition was not described by Wang et al. [39].

\section{DISCUSSION}

The aim of this review was to assess the efficacy and safety of intravenous oxycodone compared with fentanyl, morphine, sufentanil, pethidine, and hydromorphone for the management of acute postoperative pain. While a number of head-to-head RCTs were retrieved for oxycodone vs. fentanyl, oxycodone vs. morphine, and oxycodone vs. sufentanil, none were found for oxycodone vs. hydromorphone and oxycodone vs. pethidine. Despite the heterogeneity of the included studies (in terms of types of surgical procedures, study procedures, additional analgesia, and assessment methods), there were some consistencies in the results reported by the majority of the studies regarding the efficacy and safety of oxycodone compared with the other strong opioids.

Oxycodone appears to provide better analgesia than fentanyl, especially in the early postoperative period. The lower oxycodone consumption reported is important given the emphasis on opioid-sparing regimens in Enhanced Recovery After Surgery programs [41]. Safety reports, however, suggest a tendency towards more side effects with oxycodone, particularly central nervous system side effects such as nausea and dizziness. These findings indicate that the doses of oxycodone and fentanyl used were unlikely to be equi-analgesic. The dose conversion ratios between oxycodone and fentanyl used in the included studies varied from $60: 1$ to $100: 1$, likely due to the lack of standard guidelines for equi-analgesic conversion doses of the two opioids [42, 43]. Closer examination of studies that used dose ratios at the lower end of spectrum (i.e., 60-75:1) still show better analgesia and a tendency towards more side effects with oxycodone, indicating that the appropriate equi-analgesic dose ratio is likely to be less than 60:1. Further studies are warranted to fine-tune and determine the equi- analgesic doses of intravenous oxycodone and intravenous fentanyl.

For the comparisons between oxycodone and morphine, analgesic efficacy and tolerability profile appear to be comparable. Given that the dose conversion ratios of oxycodone to morphine used were 1:1 in all the included studies, the findings suggest that oxycodone and morphine are equipotent, contrary to what other reports indicate [44]. Findings from older studies of oxycodone vs. morphine for postoperative pain management also demonstrated equipotency between the two opioids $[45,46]$. One of the two included studies did however notice significantly less analgesic consumption and sedation with oxycodone than with morphine. These findings were consistent with that by Kalso et al., where oxycodone was found to be faster-acting and to cause less sedation than morphine [45]. The lower oxycodone consumption may be due to faster blood-brainbarrier transport and thus more rapid onset of analgesic action compared with morphine $[47,48]$. The active metabolite of morphine, morphine-6-glucuronide, is thought to be responsible for increased sedation, drowsiness, nausea, vomiting, and respiratory depression [49]. The studies included in this review did not assess patient satisfaction; however, findings from a study of epidural oxycodone (off-label use) vs. morphine suggest similarity in patient satisfaction between these opioids [50].

The findings of all three studies, which compared oxycodone with sufentanil for acute postoperative pain, suggest that oxycodone provides better analgesia with higher patient satisfaction. Analgesic consumption of oxycodone was lower than sufentanil when the dose conversion ratio used was 500-1000:1. The differences in analgesic consumption are likely due to the pharmacological properties of the opioids, where the longer duration of action of oxycodone compared to sufentanil reduced the need to re-dose IV-PCA as frequently $[51,52]$. The lower rate of re-dosing IV-PCA may also have resulted in greater overall patient satisfaction with oxycodone.

The mechanistic actions of the opioids should be considered when interpreting the findings on postoperative pain and side effects. 
Oxycodone is a $\mu$-receptor agonist; activity on the $\kappa$-opioid receptor has been demonstrated in animal studies $[20,21]$. Oxycodone has weaker $\mu$-receptor affinity than morphine, fentanyl, and sufentanil, which may mitigate gastrointestinal side effects caused by $\mu$-receptor agonism [19, 51]. Nonetheless, common opioidrelated side effects such as nausea and vomiting are known to be dose-dependent and are reversible with dose tapering and/or effectively managed with standard symptomatic treatment (e.g., antiemetics). Available literature suggest that oxycodone has a different pharmacological profile compared to that of morphine and that it is more effective in attenuating visceral pain $[24,25]$. This property (i.e., better antinociception in visceral pain) could give oxycodone an advantage over other opioids after surgeries in which a large component of the patient's overall postoperative pain is visceral pain. In fact, this was the basis for investigating oxycodone in many of the included studies [30, 32, 36-39]. Some studies also suggested that oxycodone has an enhanced analgesic effect on neuropathic pain $[27,28]$. Nonetheless, acute postoperative pain often involves multiple mechanisms; better designed studies are needed to confirm the clinical superiority of oxycodone over other strong opioids in treating the visceral and neuropathic components of acute postoperative pain.

Our systematic review revealed significant variability in the incidence of side effects for the respective opioids across studies. Efficacy findings were also not always consistent. Several factors may be responsible for this inconsistency. First, the studies were heterogeneous in terms of surgery types, which includes minimally invasive laparoscopic procedures, to open procedures (e.g., Cesarean section), and to even more invasive surgeries such as total hip replacement. The efficacy and need of opioids to relieve pain after minimally invasive surgery are clearly different from that after more invasive procedures. The postoperative pain intensity after laparoscopic surgeries (as were most studies) may be too low to detect significant differences in pain scores or opioid consumption. Doses of opioids used would also be lower, thus side effects may not appear as frequent or severe. Secondly, in a few studies, nurses administered opioids in pre-determined volumes rather than via IV-PCA as is used in the majority of the studies. In studies that used IVPCA, PCA program settings were not uniform in terms of bolus doses, background infusion doses (or the lack thereof), and lockout intervals. These discrepancies may have an effect on efficacy and safety outcomes and patient satisfaction. Thirdly, pain assessment scales used varied among studies (e.g., VAS, NRS 0-10, NRS 0-100) and are likely to differ in sensitivity. Some studies did not specify the method of pain assessment. Finally, side effects may be underestimated in studies that collected safety data based on patient self-reports and observations by investigators rather than via specific queries by trained healthcare professionals. All these factors precluded pooling of the data across studies in a meta-analysis. Additionally, it should be noted that all the included studies were not specifically designed to assess differences in side effects between opioid groups. Future studies with sufficient power to compare safety endpoints may thus be important.

Our systematic review of literature published over the last 10 years found only a handful of head-to-head studies comparing oxycodone with morphine, fentanyl, and sufentanil for managing acute postoperative pain. Notably, there were no head-to-head studies of oxycodone vs. pethidine or hydromorphone for the same indication during the same search period. More evidence from high-quality RCTs would be welcomed. If greater alignment in opioid administration and efficacy/safety assessment methods can be achieved in future studies, a meta-analysis may be possible to further clarify the role of oxycodone compared with the other opioids in managing acute postoperative pain.

\section{CONCLUSIONS}

Prompt and adequate postoperative pain management is crucial to a patient's postoperative recovery process. Oxycodone is known to be effective in the treatment of nociceptive, visceral, and neuropathic pain and is increasingly being used as a postoperative analgesic. The 
intravenous route is typically used in the immediate postoperative period, and conversion to oral oxycodone is initiated once oral intake of analgesia is possible. Our findings suggest that intravenous oxycodone provides superior efficacy to both fentanyl and sufentanil, and comparable efficacy to morphine with less cumulative dose consumption and less adverse events such as sedation. In some cases where oxycodone was more effective, a tendency towards more side effects was noted. Preemptive treatment of side effects and/or finetuning of doses where necessary could help to manage side effects and maximize clinical benefits. No studies comparing intravenous oxycodone with pethidine or hydromorphone were identified in this review.

The findings of this systematic review of head-to-head trials add to current evidence of the use of intravenous oxycodone for postoperative pain management, and support its integration into a multimodal analgesic approach for optimal pain management.

\section{ACKNOWLEDGEMENTS}

Funding. This study was sponsored by Mundipharma Singapore Holding Pte Ltd, Singapore. Article processing charges were funded by Mundipharma Singapore Holding Pte Ltd, Singapore. All authors had full access to the articles reviewed in this manuscript and take complete responsibility for the integrity and accuracy of this manuscript.

Medical Writing and Editorial Assistance. Medical writing and editorial support were funded by Mundipharma Singapore Holding Pte Ltd, Singapore, and provided by Bao Hui Lee and Wei Yi Kwok from Tech Observer Asia Pacific Pte Ltd.

Authorship. All authors meet the International Committee of Medical Journal Editors (ICMJE) criteria for authorship for this article and gave final approval for the version to be published.
Disclosures. Milton Raff has received speaker honorarium from and participated in advisory boards by Mundipharma. Eric Nagtalon has received speaker honorarium from and participated in advisory boards by Mundipharma. Kok Yuen Ho has received speaker honorarium and participated in advisory boards from Pfizer, Menarini, and Mundipharma. Amar Salti has served as a consultant and lecturer for Mundipharma, GE Healthcare, Pfizer, MSD, and Abbott. Jeong-Hwa Seo has participated in advisory board meetings organized by Mundipharma. Hongwei Wang has participated in advisory board meetings by Mundipharma and Baxter. Kristal Buemio is an employee of Mundipharma Pte Ltd, Singapore. Consuelo Gutierrez is an employee of Mundipharma Pte Ltd, Singapore. Yacine Hadjiat is an employee of Mundipharma Pte Ltd, Singapore. Anissa Belbachir, Aida Rosita Tantri, Tianlong Wang and Salah El-Tallawy have nothing to disclose.

Compliance with Ethics Guidelines. This article is based on previously conducted studies and does not contain any studies with human participants or animals performed by any of the authors.

Data Availability. Data sharing is not applicable to this article as no datasets were generated or analyzed during the current study.

Open Access. This article is distributed under the terms of the Creative Commons Attribution-NonCommercial 4.0 International License (http://creativecommons.org/licenses/ by-nc/4.0/), which permits any noncommercial use, distribution, and reproduction in any medium, provided you give appropriate credit to the original author(s) and the source, provide a link to the Creative Commons license, and indicate if changes were made.

\section{REFERENCES}

1. Apfelbaum JL, Chen C, Mehta SS, Gan TJ. Postoperative pain experience: results from a national survey suggest postoperative pain continues to be 
undermanaged. Anesth Analg. 2003;97(2):534-40 (table of contents).

2. Gupta A, Kaur K, Sharma S, Goyal S, Arora S, Murthy RS. Clinical aspects of acute post-operative pain management \& its assessment. J Adv Pharm Technol Res. 2010;1(2):97-108.

3. Rawal N. Current issues in postoperative pain management. Eur J Anaesthesiol. 2016;33(3):160-71.

4. Ibrahim MS, Alazzawi S, Nizam I, Haddad FS. An evidence-based review of enhanced recovery interventions in knee replacement surgery. Ann R Coll Surg Engl. 2013;95(6):386-9.

5. Montgomery R, McNamara SA. Multimodal pain management for enhanced recovery: reinforcing the shift from traditional pathways through nurseled interventions. AORN J. 2016;104(6S):S9-16.

6. Charlton E. The management of postoperative pain. Update Anaesth. 1997;7:1-7.

7. American Society of Anesthesiologists Task Force on Acute Pain M. Practice guidelines for acute pain management in the perioperative setting: an updated report by the American Society of Anesthesiologists Task Force on Acute Pain Management. Anesthesiology. 2012;116(2):248-73.

8. Celis-Rodriguez E, Birchenall C, de la Cal MA, et al. Clinical practice guidelines for evidence-based management of sedoanalgesia in critically ill adult patients. Med Intensiva. 2013;37(8):519-74.

9. Misiolek H, Cettler M, Woron J, Wordliczek J, Dobrogowski J, Mayzner-Zawadzka E. The 2014 guidelines for post-operative pain management. Anaesthesiol Intensive Ther. 2014;46(4):221-44.

10. Schug SA, Palmer GM, Scott DA, Halliwell R, Trinca J. Acute pain management: scientific evidence, fourth edition, 2015. Med J Aust. 2016;204(8):315-7.

11. The Management of Postoperative Pain Working Group. VHA/DoD clinical practice guideline for the management of postoperative pain. https://www. healthquality.va.gov/guidelines/Pain/pop/pop_ fulltext.pdf. Accessed 17 Oct 2018.

12. International Association for the Study of Pain Cancer Pain Special Interest Group Managing Acute Pain in the Developing World. https://www.iasppain.org/PublicationsNews/NewsletterIssue. aspx?ItemNumber=2078. Accessed 17 Oct 2018 .

13. Hastie BA, Gilson AM, Maurer MA, Cleary JF. An examination of global and regional opioid consumption trends 1980-2011. J Pain Palliat Care Pharmacother. 2014;28(3):259-75.
14. Fisher JE, Zhang Y, Sketris I, Johnston G, Burge F. The effect of an educational intervention on meperidine use in Nova Scotia, Canada: a time series analysis. Pharmacoepidemiol Drug Saf. 2012;21(2):177-83.

15. Lassen CL, Link F, Lindenberg N, et al. Anesthesiological acute pain therapy in Germany: telephonebased survey. Anaesthesist. 2013;62(5):355-64.

16. Pergolizzi JV Jr, Seow-Choen F, Wexner SD, Zampogna G, Raffa RB, Taylor R Jr. Perspectives on intravenous oxycodone for control of postoperative pain. Pain Pract. 2016;16(7):924-34.

17. Poyhia R. Opioids in anaesthesia: a questionnaire survey in Finland. Eur J Anaesthesiol. 1994;11(3):221-30.

18. Schaefer CP, Tome ME, Davis TP. The opioid epidemic: a central role for the blood brain barrier in opioid analgesia and abuse. Fluids Barriers CNS. 2017;14(1):32.

19. Drewes AM, Jensen RD, Nielsen LM, et al. Differences between opioids: pharmacological, experimental, clinical and economical perspectives. $\mathrm{Br} \mathrm{J}$ Clin Pharmacol. 2013;75(1):60-78.

20. Nielsen CK, Ross FB, Lotfipour S, Saini KS, Edwards SR, Smith MT. Oxycodone and morphine have distinctly different pharmacological profiles: radioligand binding and behavioural studies in two rat models of neuropathic pain. Pain. 2007;132(3):289-300.

21. Ross FB, Smith MT. The intrinsic antinociceptive effects of oxycodone appear to be kappa-opioid receptor mediated. Pain. 1997;73(2):151-7.

22. Yang PP, Yeh GC, Yeh TK, et al. Activation of deltaopioid receptor contributes to the antinociceptive effect of oxycodone in mice. Pharmacol Res. 2016;111:867-76.

23. Olesen AE, Staahl C, Arendt-Nielsen L, Drewes AM. Different effects of morphine and oxycodone in experimentally evoked hyperalgesia: a human translational study. $\mathrm{Br} \mathrm{J}$ Clin Pharmacol. 2010;70(2):189-200.

24. Staahl C, Christrup LL, Andersen SD, Arendt-Nielsen L, Drewes AM. A comparative study of oxycodone and morphine in a multi-modal, tissuedifferentiated experimental pain model. Pain. 2006;123(1-2):28-36.

25. Staahl C, Dimcevski G, Andersen SD, et al. Differential effect of opioids in patients with chronic pancreatitis: an experimental pain study. Scand J Gastroenterol. 2007;42(3):383-90.

26. Staahl C, Upton R, Foster DJ, et al. Pharmacokinetic-pharmacodynamic modeling of morphine 
and oxycodone concentrations and analgesic effect in a multimodal experimental pain model. J Clin Pharmacol. 2008;48(5):619-31.

27. Barrera-Chacon JM, Mendez-Suarez JL, JaureguiAbrisqueta ML, Palazon R, Barbara-Bataller E, Garcia-Obrero I. Oxycodone improves pain control and quality of life in anticonvulsant-pretreated spinal cord-injured patients with neuropathic pain. Spinal Cord. 2011;49(1):36-42.

28. Thibault K, Calvino B, Rivals I, et al. Molecular mechanisms underlying the enhanced analgesic effect of oxycodone compared to morphine in chemotherapy-induced neuropathic pain. PLoS One. 2014;9(3):e91297.

29. Lee $\mathrm{KH}$, Kang JH, Oh HS, et al. Intravenous oxycodone versus intravenous morphine in cancer pain: a randomized, open-label, parallel-group, active-control study. Pain Res Manag. 2017;2017:9741729.

30. Koch S, Ahlburg P, Spangsberg N, Brock B, Tonnesen E, Nikolajsen L. Oxycodone vs. fentanyl in the treatment of early post-operative pain after laparoscopic cholecystectomy: a randomised double-blind study. Acta Anaesthesiol Scand. 2008;52(6):845-50.

31. Hwang BY, Kwon JY, Kim E, Lee DW, Kim TK, Kim HK. Oxycodone vs. fentanyl patient-controlled analgesia after laparoscopic cholecystectomy. Int J Med Sci. 2014;11(7):658-62.

32. Lenz H, Sandvik L, Qvigstad E, Bjerkelund CE, Raeder J. A comparison of intravenous oxycodone and intravenous morphine in patient-controlled postoperative analgesia after laparoscopic hysterectomy. Anesth Analg. 2009;109(4):1279-83.

33. Kim NS, Kang KS, Yoo SH, et al. A comparison of oxycodone and fentanyl in intravenous patientcontrolled analgesia after laparoscopic hysterectomy. Korean J Anesthesiol. 2015;68(3):261-6.

34. Kim NS, Lee JS, Park SY, et al. Oxycodone versus fentanyl for intravenous patient-controlled analgesia after laparoscopic supracervical hysterectomy: a prospective, randomized, double-blind study. Medicine (Baltimore). 2017;96(10):e6286.

35. Park JH, Lee C, Shin Y, An JH, Ban JS, Lee JH. Comparison of oxycodone and fentanyl for postoperative patient-controlled analgesia after laparoscopic gynecological surgery. Korean J Anesthesiol. 2015;68(2):153-8.

36. Ding Z, Wang K, Wang B, Zhou N, Li H, Yan B. Efficacy and tolerability of oxycodone versus fentanyl for intravenous patient-controlled analgesia after gastrointestinal laparotomy: a prospective, randomized, double-blind study. Medicine (Baltimore). 2016;95(39):e4943.

37. Pedersen KV, Olesen AE, Drewes AM, Osther PJ. Morphine versus oxycodone analgesia after percutaneous kidney stone surgery: a randomised double blinded study. Urolithiasis. 2013;41(5):423-30.

38. Nie JJ, Sun S, Huang SQ. Effect of oxycodone patient-controlled intravenous analgesia after cesarean section: a randomized controlled study. J Pain Res. 2017;10:2649-55.

39. Wang N, Zhou H, Song X, Wang J. Comparison of oxycodone and sufentanil for patient-controlled intravenous analgesia after laparoscopic radical gastrectomy: a randomized double-blind clinical trial. Anesth Essays Res. 2016;10(3):557-60.

40. Han L, Su Y, Xiong H, et al. Oxycodone versus sufentanil in adult patient-controlled intravenous analgesia after abdominal surgery: a prospective, randomized, double-blinded, multiple-center clinical trial. Medicine (Baltimore). 2018;97(31):e11552.

41. Garimella V, Cellini C. Postoperative pain control. Clin Colon Rectal Surg. 2013;26(3):191-6.

42. Anderson R, Saiers JH, Abram S, Schlicht C. Accuracy in equianalgesic dosing. Conversion dilemmas. J Pain Symptom Manag. 2001;21(5):397-406.

43. Rennick A, Atkinson T, Cimino NM, Strassels SA, McPherson ML, Fudin J. Variability in opioid equivalence calculations. Pain Med. 2016;17(5):892-8.

44. Pereira J, Lawlor P, Vigano A, Dorgan M, Bruera E. Equianalgesic dose ratios for opioids. A critical review and proposals for long-term dosing. J Pain Symptom Manag. 2001;22(2):672-87.

45. Kalso E, Poyhia R, Onnela P, Linko K, Tigerstedt I, Tammisto T. Intravenous morphine and oxycodone for pain after abdominal surgery. Acta Anaesthesiol Scand. 1991;35(7):642-6.

46. Silvasti M, Rosenberg P, Seppala T, Svartling N, Pitkanen M. Comparison of analgesic efficacy of oxycodone and morphine in postoperative intravenous patient-controlled analgesia. Acta Anaesthesiol Scand. 1998;42(5):576-80.

47. Bostrom E, Hammarlund-Udenaes M, Simonsson US. Blood-brain barrier transport helps to explain discrepancies in in vivo potency between oxycodone and morphine. Anesthesiology. 2008;108(3):495-505.

48. Bostrom E, Simonsson US, Hammarlund-Udenaes M. In vivo blood-brain barrier transport of oxycodone in the rat: indications for active influx and 
implications for pharmacokinetics/pharmacodynamics. Drug Metab Dispos Biol Fate Chem. 2006;34(9):1624-31.

49. Riley J, Ross JR, Rutter D, et al. No pain relief from morphine? Individual variation in sensitivity to morphine and the need to switch to an alternative opioid in cancer patients. Support Care Cancer. 2006;14(1):56-64.

50. Sng BL, Kwok SC, Mathur D, et al. Comparison of epidural oxycodone and epidural morphine for postcaesarean section analgesia: a randomised controlled trial. Indian J Anaesth. 2016;60(3):187-93.

51. Deshpande CM, Mohite SN, Kamdi P. Sufentanil vs fentanyl for fast-track cardiac anaesthesia. Indian J Anaesth. 2009;53(4):455-62.

52. Leow KP, Cramond T, Smith MT. Pharmacokinetics and pharmacodynamics of oxycodone when given intravenously and rectally to adult patients with cancer pain. Anesth Analg. 1995;80(2):296-302.

53. OxyNorm $50 \mathrm{mg} / \mathrm{ml}$, solution for injection or infusion: SmPC (UK). 2018.

54. Kalso E. Oxycodone. J Pain Symptom Manag. 2005;29(5 Suppl):S47-56.

55. Kirvela M, Lindgren L, Seppala T, Olkkola KT. The pharmacokinetics of oxycodone in uremic patients undergoing renal transplantation. J Clin Anesth. 1996;8(1):13-8.

56. Kokki M, Valitalo P, Kuusisto $M$, et al. Central nervous system penetration of oxycodone after intravenous and epidural administration. $\mathrm{Br} \mathrm{J}$ Anaesth. 2014;112(1):133-40.

57. Arendt-Nielsen L, Olesen AE, Staahl C, et al. Analgesic efficacy of peripheral kappa-opioid receptor agonist CR665 compared to oxycodone in a multimodal, multi-tissue experimental human pain model: selective effect on visceral pain. Anesthesiology. 2009;111(3):616-24.

58. Product Monograph: OxyNorm ${ }^{\circledR}$ Injection (Oxycodone hydrochloride solution for injection or infusion). Napp Pharmaceuticals Limited, Cambridge, UK.

59. Aubrun F, Mazoit JX, Riou B. Postoperative intravenous morphine titration. $\mathrm{Br} \mathrm{J}$ Anaesth. 2012;108(2):193-201.

60. United States FDA prescribing information: Morphine Sulfate injection, for intravenous or intramuscular use. https://www.accessdata.fda.gov/ drugsatfda_docs/label/2016/204223s006lbl.pdf. Accessed 16 Mar 2018.
61. Trivedi M, Shaikh S, Gwinnut C. Pharmacology of opioids. Update Anaesth. 2008;24(2):118-24.

62. United States FDA prescribing information: Fentanyl Citrate Injection, for intravenous or intramuscular use. https://www.accessdata.fda.gov/ drugsatfda_docs/label/2016/016619s038lbl.pdf. Accessed: 16 Mar 2018.

63. Fentanyl injection. Fentanyl solution for injection 50 micrograms/ml: New Zealand data sheet. 2017.

64. United States FDA prescribing information: Sufentanil Citrate Injection, for intravenous and epidural use. https://www.accessdata.fda.gov/drugsatfda docs/label/2016/019050s034lbl.pdf. Accessed $1 \overline{6}$ Mar 2018.

65. Willsie SK, Evashenk MA, Hamel LG, Hwang SS, Chiang YK, Palmer PP. Pharmacokinetic properties of single- and repeated-dose sufentanil sublingual tablets in healthy volunteers. Clin Ther. 2015;37(1):145-55.

66. Freye E, Latasch L, Portoghese PS. The delta receptor is involved in sufentanil-induced respiratory depression-opioid subreceptors mediate different effects. Eur J Anaesthesiol. 1992;9(6):457-62.

67. Monk JP, Beresford R, Ward A. Sufentanil. A review of its pharmacological properties and therapeutic use. Drugs. 1988;36(3):286-313.

68. Chan K, Tse J, Jennings F, Orme ML. Pharmacokinetics of low-dose intravenous pethidine in patients with renal dysfunction. J Clin Pharmacol. 1987;27(7):516-22.

69. United States FDA prescribing information: DEMEROL (meperidine hydrochloride injection), for subcutaneous, intramuscular, and intravenous use. https://www.accessdata.fda.gov/drugsatfda docs/label/2016/021171s024s025lbl.pdf. Accessed 16 Mar 2018.

70. Clark RF, Wei EM, Anderson PO. Meperidine: therapeutic use and toxicity. J Emerg Med. 1995;13(6):797-802.

71. United States FDA prescribing information: DILAUDID $^{\circledR} \quad$ INJECTION (hydromorphone hydrochloride) and DILAUDID-HP ${ }^{\circledR}$ INJECTION (hydromorphone hydrochloride), for intravenous, intramuscular, or subcutaneous use. https://www. accessdata.fda.gov/drugsatfda_docs/label/2017/ 019034s029lbl.pdf. Accessed 16 Mar 2018.

72. Murray A, Hagen NA. Hydromorphone. J Pain Symptom Manag. 2005;29(5 Suppl):S57-66. 